\title{
A língua estrangeira no país dos espelhos: uma reflexão sobre o limbo metodológico
}

\section{Foreign language in the mirror's land: a reflection about the methodological limbo}

\author{
Deise Cristina de Lima Picanço*
}

\begin{abstract}
RESUMO
As propostas metodológicas para o ensino de línguas estrangeiras das últimas décadas, ao optarem por adotar um referencial teórico sociointeracionista na definição mais geral da concepção de linguagem e ensino e outro, mais formalista, na fundamentação dos procedimentos empíricos da sala de aula, acabaram por nos colocar numa espécie de limbo metodológico, ou seja, uma metodologia imprecisa teoricamente e confusa na prática. Nesse sentido, este artigo propõe uma discussão acerca dos problemas teórico-metodológicos do ensino de LEs, partindo de uma reflexão sobre o enunciado, fundamentada, por sua vez, por uma concepção de linguagem mais ampla, inspirada nas formulações teóricas dos pensadores do Círculo de Bakhtin.

Palavras-chave: ensino de línguas, Círculo de Bakhtin, parâmetros curriculares para LEs, lingüística aplicada ao ensino de LEs.
\end{abstract}

\begin{abstract}
The methodological proposal for foreign language teaching of the last decades has created a kind of methodological limbo, in other words, a methodology that is not-precisely in its theory and confuse in its practice. This situation resulted for an option by a socio-interactionist reference in a more general definition of language and teaching conception. In this way, here there is a proposal for a discussion about theoretical and methodological problems in

* Graduada em Letras Português/Espanhol e Mestre em Educação. Professora de Metodologia e Prática de Ensino de Língua Estrangeira Moderna do DTPEN/UFPR.
\end{abstract} dedeclp@terra.com.br 
FL teaching. This reflection starts with a reflection about utterance, that is particularly based on a wider language conception inspired on theoretical formulations of Bakhtin's Circle thinkers.

Key-words: language teaching, Bakhtin Circle, curricula parameters for FL, applied linguistic for FL teaching.

Quando nos deparamos com propostas metodológicas de ensino de línguas de base sociointeracionista, esperamos que elas estejam fundamentadas em uma perspectiva teórica sociohistórica. Em linhas gerais, essa perspectiva tem sido defendida em artigos, livros e propostas metodológicas que concebem a linguagem em uso como o conteúdo privilegiado e propõem um viés comunicativo ao ensino de línguas estrangeiras. Isso parece significar que o que se quer trabalhar em sala de aula é a língua como meio de interação social, pretendendo garantir ao aluno uma autonomia discursiva. E é preciso reconhecer que essa postura representa um grande avanço em relação às orientações normativistas e às abordagens metodológicas estruturalistas.

A tentativa de configurar tais propostas metodológicas, fundamentadas em pressupostos sociointeracionistas, tem gerado, com muita recorrência, uma grande quantidade de referências e citações de alguns pensadores em especial. Encontramos, freqüientemente, referências e citações de textos de Vygotsky - como pensador preocupado com a questão da aprendizagem e da formação da consciência através dos signos lingüísticos - e, muitas vezes ao lado dele, também nos deparamos com referências e citações dos textos dos pensadores do Círculo de Bakhtin, principalmente das formulações feitas por Voloshinov, em Marxismo e Filosofia da Linguagem, e por Bakhtin, em Gêneros do Discurso.

No entanto, embora seja reconhecida a importância heurística desses autores, pouco efetivamente foi feito, até o momento, no sentido de evidenciar a aplicabilidade do seu pensamento. Essas referências e citações, ainda que estejam disseminadas em livros, artigos e propostas metodológicas - oficiais ou não -, acham-se desconectadas, nesses textos, das propostas para as práticas de sala de aula.

Destituídas de sua aplicabilidade, algumas dessas formulações teóricas foram transformadas em máximas - como, por exemplo, linguagem e sociedade são inseparáveis, a linguagem é dialógica, ou então, vivemos num mundo plurilíngüe - que parecem apenas buscar consensos, prejudicando o aprofundamento de nossas discussões e a definição de posições teóricas de fato. 
Uma das consequiências disso é uma certa neutralização do potencial heurístico dessas idéias, ou seja, da potencialidade que elas têm de provocar novos debates - ainda necessários - sobre o ensino de línguas, tornando-as inconsistentes. Isso impossibilita a contribuição efetiva dessas teorias no enfrentamento dos problemas do cotidiano de quem ensina e de quem quer aprender uma língua. Essa inconsistência acaba gerando uma expectativa de resolver tais problemas práticos da sala de aula através de outras teorias - como a lingüística textual, a teoria dos atos de fala, semântica, entre outras. E essa tem sido uma das formas mais freqüentes de solucionar o problema teórico-metodológico encontrado pela lingüística aplicada: um referencial teórico na definição mais geral da concepção de linguagem e ensino e outro, mais formalista, na fundamentação dos procedimentos empíricos da sala de aula.

Essa ambigüidade faz com que professores, mesmo sem compreender suas implicações teórico-metodológicas, acabem optando, numa atitude de ordem prática apenas, por uma postura eclética e contraditória: pegar um pouquinho de cada método e ir aplicando aqui e ali, porque assim o aluno que não aprendeu de um jeito deve aprender do outro.

Ainda que tentar diversificar as aulas conforme as necessidades do aluno seja uma atitude louvável e até desejável, essa postura eclética, além de não resolver a questão, faz perpetuar a impressão de que o ato de ensinar e aprender línguas, sem uma adequada potencialidade de generalização teórico-metodológica, depende exclusivamente da capacidade do professor de realizar malabarismos e conseguir fazer com que o aluno, apesar de tudo, aprenda.

Nos parece claro, portanto, que estamos enredados numa metodologia imprecisa teoricamente e confusa na prática. Por isso, ressaltamos a necessidade de refletir sobre algumas das formulações teóricas que permanecem numa espécie de limbo metodológico. Pretendemos (re)inserir, nos debates sobre ensino de línguas estrangeiras, particularmente, a fertilidade heurística do pensamento do Círculo de Bakhtin e suas implicações na construção de uma metodologia de ensino de base sociológica.

Nesse sentido, gostaríamos de fazer referência a um artigo, publicado nesta mesma revista, em 1999, em que Carlos Alberto Faraco e Gilberto de Castro já discutiam o problema da falta de uma reflexão teórica consistente que pudesse orientar o trabalho com língua portuguesa na escola. Ao ler esse artigo, relativamante recente, fica evidente que parte de suas reflexões acerca das contribuições da lingüística aplicada atual ao ensino de língua materna também poderiam extender-se ao ensino de línguas estrangeiras. 
Os autores discutiam, nesse artigo, a necessidade de uma reflexão teórica que pudesse de fato respaldar as propostas de mudanças práticas para o ensino de português que foram defendidas por profissionais de várias áreas, inclusive a lingüística, nas últimas décadas.

Percebendo que os autores do Círculo de Bakhtin tinham uma presença relativamente grande nesses debates metodológicos, sem o devido aprofundamento teórico, Faraco e Castro chamavam a atenção para o fato de que a ponte entre a teoria e a prática estava ainda por se fazer em relação às idéias lingüísticas daqueles pensadores e o ensino de linguagem.

Algumas das questões importantes, levantadas pelos autores no artigo, são o uso da gramática normativa no ensino de língua materna e a questão do texto como objeto de ensino. Sua preocupação era mostrar que

Quando os lingüistas criticam a prática maniqueísta e prescritiva da escola, estão rejeitando os seus fundamentos, ou seja, a concepção de linguagem dos gramáticos. (...) Ao elegerem o texto como objeto central do ensino, eles estão implicitamente sugerindo um outro entendimento do que vem a ser a linguagem. Agora, ao invés de um olhar monológico sobre a relação do ser humano com a linguagem, temos uma proposta que assume, mesmo que implicitamente, que o aprendizado com a linguagem se dá por meio do uso que fazemos dela na interação (oral ou escrita) que estabelecemos com o outro, seja ele real ou virtual (FARACO; CASTRO, 1999, p. 181).

Os autores evidenciam, portanto, que por trás dessas soluções práticas há uma forma diferenciada de pensar a linguagem e que essa concepção deveria estar orientando as reflexões metodológicas necessárias à transformação de tais propostas em mudanças efetivas. Por isso, os autores discordam dos procedimentos defendidos pelos lingüistas. Para eles, é um equívoco, por exemplo, que, ao discutir o ensino de língua materna, propondo que ele deve ser feito através da leitura e produção de textos, entenda-se que "basta exercitar a intuição e abandona-se totalmente o ensino de gramática (...)" (p. 181).

Segundo os autores, "apesar de todas as críticas que se possa fazer à gramática em virtude de suas imperfeições e impropriedades conceituais e empíricas, temos de admitir que ela ainda é a principal fonte de referência da normatização da linguagem-padrão falada e escrita do país. Além disso, a tradição gramatical nos fornece uma metalinguagem bastante útil para 
tratar das línguas humanas, metalinguagem que a própria lingüística contemporânea pouco alterou". (p. 182, grifo nossso)

Acreditamos, assim como os autores, que não podemos simplesmente descartar toda a construção teórica dos gramáticos como se ela não fizesse parte da cultura letrada com a qual boa parte dos nossos alunos passa a estar em contato assim que entra na escola e com a qual ainda nos enfrentamos no campo dos estudos lingüísticos.

Se pensarmos no ensino de línguas estrangeiras, de um modo geral, muitos são os alunos adultos que preferem a reflexão lingüística - porque já a dominam - ao aprendizado intuitivo e aos quadros esquemáticos dos livros didáticos. Isso não quer dizer que tenhamos que voltar a ensinar - conforme a tradição normativista - a classificação dos substantivos e dos advérbios com base nas obras de autores consagrados da literatura. Queremos apenas que a atividade reflexiva, teórica, faça parte do conjunto de atividades de sala de aula como uma forma produtiva de dar, progressivamente, mais autonomia ao aluno na busca de soluções para questões normativas que, seguramente, lhe serão impostas em situações de uso formal da linguagem, principalmente escrita.

Da mesma forma, Faraco e Castro são muito precisos e explicitam bem a fragilidade da aplicação, ao ensino, do mesmo tratamento que algumas áreas da lingüística dão ao texto como seu objeto de estudo. Se a lingüística mais tradicional teria pouco a dizer sobre o assunto, quando nos aproximamos da lingüística textual, "o que percebemos é mais uma análise das relações internas referentes a ele (reparemos, por exemplo, na excessiva bibliografia hoje existente sobre as discussões de coesão e coerência) do que uma preocupação conceitual que busque uma generalização sobre a noção de texto que consiga transcender os elementos meramente formais e de ligação interna" (p. 183). Essa forma de abordagem do texto, com a mesma excessiva presença de trabalhos de coesão e coerência, é bastante visível no ensino de línguas estrangeiras, principalmente nas propostas metodológicas centradas na habilidade de leitura.

Por isso, embora muitos professores de línguas estrangeiras não conheçam as orientações dos Parâmetros Curriculares Nacionais/Línguas Estrangeiras - tanto dos $3^{\circ}$ e $4^{\circ}$ ciclos do ensino Fundamental quanto do Ensino Médio -, publicados em 1998, acreditamos que eles refletem tendências muito fortes no ensino de línguas nas últimas décadas: uma perspectiva sociointeracionista de linguagem e ensino e a ênfase na habilidade leitura. Como uma síntese dessas tendências, tomaremos como referência 
para nossas reflexões os Parâmetros Curriculares para o $3^{\circ}$ e o $4^{\circ}$ ciclos por apresentarem mais detalhes da sua proposta teórico-metodológica.

Os autores fazem, inicialmente, uma discussão no sentido de justificar sua proposta, levantando dados importantes acerca do ensino de línguas no país. Certamente, muitos leitores devem identificar situações, ali descritas, como muito próximas às de sua realidade.

Outro ponto positivo do documento é tentar trazer, numa linguagem de acesso relativamente fácil, as discussões atuais e mais destacadas na área de metodologia do ensino de línguas estrangeiras. E talvez esteja aí, também, a sua fragilidade: o não aprofundamento de discussões importantes, reificando termos como discurso, dialogismo e alteridade, o que acaba por tornar imprecisas as noções de enunciado, texto, comunicação e interação.

As definições de alguns termos importantes na conformação de uma metodologia sociointeracionista são dadas sem que se faça qualquer referência à teoria ou aos autores que estariam fundamentando tais definições. O termo discurso, por exemplo, foi definido da seguinte forma: "discurso é uma concepção de linguagem como prática social por meio da qual as pessoas agem no mundo, considerando-se as condições não só de produção como também de interpretação" (BRASIL/MEC/SEF, 1998, p. 27). No entanto, parece-nos que a definição do termo base discursiva está pautada por outra concepção de discurso pois se caracteriza pelo "domínio da capacidade que possibilita as pessoas se comunicarem umas com as outras por meio do texto escrito ou oral" (p. 20). E uma terceira forma de conceber o discurso está na construção do aluno como sujeito do discurso que "se relaciona ao desenvolvimento de sua capacidade de agir no mundo por meio da palavra em língua estrangeira nas várias habilidades comunicativas" (p. 19). Não fica claro, portanto, qual dessas três formas de conceber a discursividade é determinante para os autores dos Parâmetros: como prática social, como troca de informações através do texto ou como o conjunto das habilidades comunicativas do falante.

Essa imprecisão conceitual também se torna visível quando os autores tentam mostrar de que forma os conhecimentos sistêmico, de mundo e da organização textual condicionam a compreensão e a produção de textos na língua estrangeira. Primeiramente, vejamos como tais formas de conhecimento são definidas: "o conhecimento sistêmico envolve os vários níveis da organização lingüística que as pessoas têm: os conhecimentos léxico-semânticos, morfológicos, sintáticos e fonéticofonológicos. Ele possibilita que as pessoas, ao produzirem enunciados, 
façam escolhas gramaticalmente adequadas ou que compreendam enunciados apoiando-se no nível sistêmico da língua (...)"; "o conhecimento de mundo se refere ao conhecimento convencional que as pessoas têm sobre as coisas do mundo, isto é, seu pré-conhecimento do mundo (...). Esses conhecimentos, organizados na memória como blocos de informação, variam de pessoa para pessoa, pois refletem as experiências que tiveram, os livros que leram, os países onde vivem etc.(...)"; "o terceiro tipo de conhecimento que o usuário de uma língua tem engloba as rotinas interacionais que as pessoas usam para organizar a informação em textos orais e escritos. (...) Em geral, o textos orais e escritos podem ser classificados em três tipos básicos: narrativos, descritivos e argumentativos (...)." (p. 29-31).

Seria possível inferir, a partir destas e outras passagens, que texto e enunciado, para os autores, são intercambiáveis entre si. Mas expressam exatamente a mesma coisa? Um enunciado é sempre um texto ou pode ser formado por um conjunto de signos não verbais? O que compõe um enunciado, então? E o que compõe o texto: um conjunto ordenado de informações? Se texto e enunciado são intercambiáveis, podemos usar os mesmos critérios para classificá-los, como, por exemplo, suas características internas, pela maneira como as informações são organizadas, seqüenciadas e conectadas internamente na massa verbal do texto ou pelo tipo de função social e cultural que exerce num dado campo de atividades sociais humanas?

Da mesma forma, ficamos na dúvida com relação ao que concebemos como comunicação. Comunicar-se é trocar informações originadas na mente do falante ou é interagir no mundo a partir de práticas discursivas? As práticas discursivas dependem da situação e da intenção do falante apenas ou também do conjunto de valores sociais, culturais, morais etc. que permeiam e condicionam o seu dizer?

Embora nenhuma destas questões possua uma única e fácil resposta, acreditamos que é possível - e necessário - assumir uma posição diante delas para que possamos superar o limbo metodológico em que a imprecisão e confusão teórico-metodológica das últimas décadas nos colocaram.

Um outro momento em que as orientações teóricas são imprecisas é na parte das Orientações Didáticas, em que os autores tentam explicar de que forma os três tipos de conhecimento condicionam tanto a leitura como a produção de texto na aula de língua estrangeira: 
...o conhecimento de mundo tem um papel primordial, pois, ao ler, o aluno cria hipóteses sobre o significado que está construindo com base em seu pré-conhecimento. Por exemplo, ao encontrar a palavra "cinema" em um texto, o leitor aciona o seu conhecimento sobre cinema. Assim, caminha pelo texto projetando coerência por meio da representação do mundo textual que vai elaborando com base do que se sabe sobre cinema (p. 90).

Da mesma forma, o conhecimento da organização textual

...facilita a leitura ao indicar para o aluno como a informação está organizada no texto. Por exemplo, ao ler uma história, o leitor-aluno, confiando em seu conhecimento da organização de histórias, sabe que sua compreensão será balizada pelo modo como as histórias se organizam. Assim após encontrar a situação da história em que estão apresentados os personagens e o contexto em que atuam, o aluno se prepara para encontrar o problema, em seguida a solução e a avaliação (p. 90).

E, finalmente, de acordo com os Parâmetros,

...o conhecimento sistêmico contribui para a ativação e confirmação das hipóteses que o aluno está elaborando. Nos estágios iniciais de aprendizagem, o conhecimento referente aos itens lexicais é crucial, já que facilita a ativação de conhecimento de mundo do aluno. O conhecimento da morfologia da Língua Estrangeira, ao indicar o papel gramatical do item, colabora para a compreensão (p. 90).

Os autores dos Parâmetros, nestes exemplos, mostram que sua concepção metodológica acerca da leitura está muito mais voltada para os fatores internos dos textos, ainda que dependam da ativação do conhecimento prévio do aluno. Suas preocupações em relação aos problemas que o leitor pode enfrentar estão direcionadas ao aspecto das relações entre as palavras, entre as frases e entre o texto e o seu co-texto num limitado sentido de contextualização (contexto imediato, intenções do falante/autor, práticas conversacionais e conhecimento de mundo). 
Da mesma forma, ao considerar como seus três tipos básicos de texto o narrativo, o descritivo e o argumentativo, os autores revelam que, no fundo, o modelo abstrato de linguagem é o que fundamenta sua opção téorico-metodológica de fato. Para que serve este tipo de classificação se os próprios autores vão dizer que "esses três tipos básicos são usados na organização de vários outros tipos de textos, que têm funções diferentes na prática social (...)"? (p. 31). Quando é que na prática social encontramos estes três tipos básicos, ou seja, quando encontramos um texto essencialmente narrativo, descritivo ou argumentativo? Se eles não existem na prática social, então poderíamos dizer que eles não existem fora das aulas de redação da escola, em classificações abstratas.

Pautados pelas discussões feitas no interior da lingüística aplicada, os autores revelam uma postura sobre a qual chamávamos a atenção no início do texto e que tem sido uma das formas de solucionar o problema teóricometodológico: um referencial teórico na definição mais geral da concepção de linguagem e ensino e outro, mais formalista, na fundamentação dos procedimentos de sala de aula.

Um outro campo dos estudos lingüísticos freqüentemente requisitado pelos lingüistas aplicados na solução dos problemas metodológicos com o texto e que também aparece como referência nos Parâmetros é a análise do discurso.

No entanto, como já vimos, não é possível precisar de que noção de discurso se trata e, portanto, fica difícil entender o que se quer dizer com ser discursivo na definição dos objetivos de ensino:

...possibilitar que o aluno, ao se envolver nos processos de construir significados nessa língua, se constitua em um ser discursivo no uso de uma língua estrangeira (BRASIL/MEC/SEF, 1998, p. 29).

No geral, embora seja a disciplina mais adequada para se estudar o texto como linguagem em uso, a análise do discurso que serve de referência à lingüística aplicada, segundo Faraco e Castro, "é hoje uma teoria híbrida sobre a linguagem: de um lado, ela estica o olhar para ver se descobre os mistérios da linguagem viva; e, de outro, não consegue de fato exorcizar o modo estruturalista de ver a linguagem sob o prisma das relações formais" (FARACO; CASTRO, 1999, p. 183). 
Além das propostas de ensino centradas na habilidade de leitura, as propostas pautadas no ensino comunicativo de línguas estrangeiras também buscam respaldo na análise do discurso. Ao analisar os trabalhos de autores da principal corrente de pesquisa em lingüística aplicada à análise do discurso, Alastair Pennycook nos chama a atenção para o fato de que a concepção de discurso como um fenômeno suprassentencial poderia - nos trabalhos que privilegiam somente o material verbal (nível micro: lexical, gramatical, entonacional/fonológico) ou mesmo naqueles em que é levado em conta o chamado contexto (intenções dos falantes, conhecimento de mundo, estrutura do texto/conversação) - explicar tanto a rápida extensão e aceitação da análise do discurso pela lingüística aplicada quanto as suas limitações.

De acordo com PENNYCOOK (1994), uma das possíveis motivações para o interesse da lingüística aplicada pela análise do discurso pode ser explicada por uma necessidade pragmática de entender melhor a linguagem em uso para o ensino de língua e a aplicação da teoria lingüística a uma teoria do ensino de línguas. Por isso, os trabalhos de Coulthard e Widdowson, por exemplo, foram tão bem aceitos por muita gente envolvida com o ensino. A ampliação epistemológica alcançada com os trabalhos desses autores se deu no sentido de compreender a importância da comunicação real na sala de aula, da aquisição da linguagem como um processo social e da noção de competência comunicativa como aspecto fundamental para o ensino de línguas. No entanto, quando a lingüística aplicada tenta ir além do paradigma lingüístico dominante, em que as práticas de linguagem são apenas a atualização do código, ela passa a focar predominantemente as relações entre as estruturas e seus contextos descontextualizados.

Conseqüentemente, para Pennycook, a lingüística aplicada, ainda que incorpore pressupostos da análise do discurso, por sua abordagem formal e seu limitado entendimento do que seja o contexto discursivo, não consegue superar sua estreita condição de entendimento das relações entre o sujeito, a linguagem e a ideologia:

...while discourse analysis as conceived in applied linguistics had opened up a number of important dimensions for language teaching, at the same time, by focusing on the relationship between language forms and a limited sense of context (immediate surroudings, speakers' intentions, backgroud knowledge, or conversational rules), it tended to be confined to a narrow understanding of the larger social, cultural, and ideological forces that 
influence our lives. It does not seem sufficient to stopwith a version of discourse analysis that posits a completely free-willed subject and language use free of ideological conditions (PENNYCOOK, 1994, p. 121).

Chamando nossa atenção para essas mesmas limitações, Faraco e Castro defendem a necessidade de superá-las através de uma reflexão teórica capaz de propor soluções para os problemas com o texto ou com a gramática, "mas que também seja, por força de uma heurística mais abrangente" (p. 183), capaz de antever novos tipos de problemas.

Sem a pretensão de dar a última palavra sobre o assunto, os autores pretendiam, no sentido de dar uma contribuição com relação ao tema, analisar alguns problemas relativos ao ensino de língua materna à luz da teoria do Círculo de Bakhtin.

Ao mostrar como essa teoria pode contribuir para o entendimento do que deve ser o trabalho com a linguagem em uso, os autores nos mostram porque muitos lingüistas têm dificuldade para lidar com as formalizações sem cair no extremo de negá-las totalmente (como no caso do abandono das formalizações dos gramáticos tradicionais) ou de colocá-las no centro absoluto das preocupações. Para Voloshino, "todo procedimento abstrato, para se legitimar, deve ser justificado por um propósito teórico e prático preciso. Uma abstração pode ser fecunda ou estéril, útil para certos fins e determinadas tarefas e não para outras" (BAKHTIN; voloshinov, 1992, p. 96). A dificuldade de entender essa relativização, por parte de muitos lingüistas, se dá por conta do equívoco de tentar fazer com que o objeto teórico corresponda ao todo do objeto empírico, ou seja, que a formalização corresponda ao todo da língua.

Por outro lado, ao partir de uma concepção de língua de base sociológica e histórica, a perspectiva de Voloshinov nos permite ver a gramática como uma descrição sempre parcial e circunstancial de alguns fatos da língua. De acordo com essa perspectiva, seria possível, segundo Faraco e Castro, (re)instaurarmos o trabalho com a gramática tradicional dentro da sala de aula. Desta forma, poderíamos fazer dela mais um livro de consultas, assim como o dicionário, que pode não resolver todos os nossos problemas mas, ainda assim, é um importante instrumento auxiliar no aprendizado de línguas.

Da mesma forma, ao refletir sobre os problemas do texto, Faraco e Castro fazem novamente uma ressalva com relação à dificuldade que a lingüística tem, pelo excessivo papel dado às relações formais, para "en- 
xergar o texto fora de seus limites internos. Não por acaso é comum entre os lingüistas falar-se, nesse caso, numa 'gramática do texto"' (p. 190).

Para entender a idéia de texto colocada pelos autores do Círculo de Bakhtin, e defendida por Faraco e Castro, é necessário, antes de mais nada, compreender que, embora não tenham usado o termo texto, as reflexões feitas sobre o conceito de enunciado - particularmente por Bakhtin e Voloshino - poderiam corresponder a formulações em torno de um conceito de texto como unidade de linguagem em uso.

Um dos problemas colocados por Bakhtin na discussão sobre o conceito de enunciado é a confusão que muitos lingüistas de sua época faziam, e que poderíamos dizer que é a mesma que se faz hoje, entre a oração, unidade de língua, e o enunciado, unidade da comunicação verbal. Para ele,

Muitos lingüistas (no campo da sintaxe) são prisioneiros dessa confusão; o que estudam é, na realidade, uma espécie de híbrido da oração (unidade da língua) e do enunciado (unidade da comunicação verbal). As pessoas não trocam orações assim como não trocam palavras (numa acepção rigorosamente lingüística), ou combinações de palavras, trocam enunciados constituídos com a ajuda das unidades da língua - palavras, conjunto de palavras, orações; mesmo assim, nada impede que o enunciado seja constituído de uma única oração, ou de uma única palavra por assim dizer, de uma unidade de fala (o que acontece sobretudo na réplica do diálogo), mas não é isso que converterá uma unidade da língua numa unidade da comunicação verbal. (BAKHTIN, 2000, p. 297)

Esse híbrido - que podemos encontrar nas frases ou mesmo nos diálogos inventados dos livros didáticos - acaba por descaracterizar tanto a oração - unidade signicante da língua - como o enunciado - entendido como unidade contextualizada da comunicação verbal. A forma de organização do enunciado, embora necessite do aparato técnico da oração, não corresponde exatamente aos aspectos sistêmicos da língua. $\mathrm{O}$ enunciado se organiza em formas relativamente estáveis determinadas pelas condições materiais de comunicação.

Estas formas relativamente estáveis de enunciados, chamadas por Bakhtin de gêneros do discurso, correspondem a formas típicas criadas por esferas de atividades humanas (científicas, religiosas, jurídicas, ar- 
tísticas, etc.), que se desenvolveram ao longo do tempo. Por isso, "a riqueza e a variedade dos gêneros do discurso são infinitas, pois a variedade virtual da atividade humana é inesgotável, e cada esfera dessa atividade comporta um repertório de gêneros do discurso que vai diferenciando-se e ampliando-se à medida que a própria esfera se desenvolve e fica mais complexa" (Bakhtin, 2000, p. 279). Os gêneros do discurso comportam todas as formas conversacionais da oralidade e o conjunto amplamente diversificado dos enunciados escritos desde as cartas até os romances, os documentos de toda ordem e todo tipo de enunciado científico. Portanto, não há correspondência entre a noção reducionista e abstrata de texto, apresentada nos Parâmetros e explicitada anteriormente, e a noção de texto/enunciado do Círculo de Bakhtin, defendida por Faraco e Castro.

Conseqüentemente, entender a natureza do enunciado - e dos gêneros do discurso como formas relativamente estáveis de enunciados - torna-se importante para todo e qualquer estudo lingüístico, de qualquer natureza, pois estudar o enunciado é uma maneira de delimitar o campo da oração:

O estudo da natureza do enunciado e dos gêneros do discurso tem uma importância fundamental para superar as noções simplificadas acerca da vida verbal, a que chamam o "fluxo verbal", a comunicação, etc., noções estas que ainda persistem em nossa ciência da linguagem. Irei mais longe: o estudo do enunciado, em sua qualidade de unidade real da comunicação verbal, também deve permitir compreender melhor a natureza das unidades da língua (da língua como sistema) as palavras e as orações. (BAKHTiN, 2000, p. 287)

Ao definir o enunciado concreto, em Discurso na vida, discurso na arte, ${ }^{l}$ Voloshinov nos mostra, que, na vida, o discurso verbal é plenamente não autosuficiente. Ele está vinculado de tal forma à situação pragmática que o engendrou que forma com ela uma unidade indissolúvel. E tudo o que

1 VOLOSHINOV, V. N. Slovo v zhizni i slovo v poesie. Zvezda, n. 6, 1926. Usamos, aqui, como referência, a tradução feita por Faraco e Tezza, para uso didático, que tomou como base a tradução inglesa de I. R. Titunik, "Discourse in life and discourse in art concerning sociological poetics", publicada em VOLOSHINOV, V. N. Freudism. New York: Academic Press, 1976. 
compõe a situação pragmática extraverbal, ainda que faça parte do todo do enunciado, não está dita em palavras: faz parte daquilo que o autor chamou de presumido. $\mathrm{O}$ enunciado verbal concreto, portanto, é composto de uma parte material, percebida, dita em palavras, e outra parte que é presumida. Para compreender um enunciado concreto é preciso saber que o interlocutor disse tudo o que tinha a dizer e conhecer o contexto extraverbal - espacial e ideacional - que o gerou. Tomada isoladamente, a parte material do enunciado, ou seja, seu componente verbal, perde a totalidade de sua significação e apenas potencialmente pode significar alguma coisa. Nesse caso, estaremos no campo da oração e não mais do enunciado. Conseqüientemente, como unidade de comunicação verbal, é o enunciado que dá sentido à oração - e às palavras que formam a oração - e não o contrário, como pode parecer à lingüística estrutural. Portanto, os autores dos Parâmetros, como podemos ver, invertem a questão ao centrar seu foco na palavra, no item lexical, fazendo com que o enunciado se transforme antes num conjunto de orações para depois revesti-lo com um contexto, até conseguir transformá-lo num semi-enunciado, num híbrido entre a unidade de língua e a unidade de comunicação verbal.

O conceito de enunciado, portanto, é importante para pensarmos qualquer tipo de abordagem do texto como unidade de comunicação, ou seja, ele torna-se a chave para entendermos tanto a leitura quanto a produção de texto na sala de aula. Recuperando novamente as reflexões de Faraco e Castro, podemos dizer que:

Em suma, uma boa leitura tem que ser capaz de preencher os claros e os implícitos indicados no texto, reconstruindo dessa forma o referencial amplo do dizer do autor. Esse é o primeiro passo na direção de uma possibilidade valorativa do aluno em relação ao texto do autor. A nosso ver, esse deve ser um dos grandes objetivos do trabalho de leitura, uma vez que o exercício de confronto com a palavra do outro é um fator preponderante na formação da subjetividade discursiva do nosso aluno (p. 191).

Com relação ao trabalho com a produção de texto, os autores nos chamam a atenção para a importância da noção de gênero discursivo considerando que, para Bakhtin, 
Assimilamos as formas da língua somente nas formas assumidas pelo enunciado juntamente com essas formas. As formas da língua e as formas típicas de enunciados, isto é, os gêneros do discurso, introduzem-se em nossa experiência e em nossa consciência juntamente e sem que sua estrita correlação seja rompida. Aprender a falar é aprender a estruturar enunciados (porque falamos por enunciados e não por orações isoladas e, menos ainda, é obvio, por palavras isoladas). Os gêneros do discurso organizam nossa fala da mesma forma que a organizam as formas gramaticais (sintáticas). (BAKHTIN, 2000, p. 302)

Portanto, estudar os gêneros do discurso seria a forma mais adequada de trabalhar linguagem em uso tendo como pressuposto que o trabalho sobre o aspecto formal deve ter em contrapartida uma razão interacional. Se, assim como sugerem os autores, formos dar uma rápida olhada na grande maioria dos materiais didáticos, sejam livros ou propostas metodológicas, veremos que sua concepção limitada de texto e contexto acaba restringindo em muito a variedade de gêneros do discurso que apresentam. Normalmente, o que encontramos são fragmentos de textos literários, diálogos situacionais e pequenos textos informativos. Nos livros didáticos, temos o agravante de que, além dos diálogos, os pequenos textos que encontramos nem sempre são autênticos, aumentando ainda mais a artificialidade da sala de aula. Isso reduz as oportunidades de interação do aluno com as diferentes formas de comunicação, limitando suas possibilidades de aprendizado.

Por isso, para Faraco e Castro, é preciso oportunizar, na escola, o contato do aluno com os mais variados gêneros discursivos. Porém, isso não quer dizer que basta ler tipos diferentes de textos para aprender a produzi-los, "é preciso também estimular a sua produção, afinal, a linguagem, num sentido amplo, aprende-se mesmo é na interação" (p. 193).

Uma última contribuição e, acreditamos, a mais importante para podermos repensar a linguagem na escola vem da definição de Bakhtin do que seja o plurilingüismo - ou heteroglossia. Entendida como toda estratificação interna de uma língua nacional, resultante da estratificação social da comunidade de que faz parte, a heteroglossia, para o autor, é a condição básica e necessária para que a linguagem funcione, para que os nossos enunciados façam sentido nos momentos de interação socioverbal que organizam nossas vidas. E esta seria a condição básica, de acordo com o autor, para o desenvolvimento do romance como o gênero discursivo que melhor representa o evento da vida. Desta forma, 
...a estratificação interna de uma língua nacional única em dialetos sociais, maneirismos de grupos, jargões profissionais, linguagens de gêneros, fala das gerações, das idades, das tendências, das autoridades, dos círculos e das modas passageiras, das linguagens de certos dias e mesmo de certas horas (cada dia tem sua palavra de ordem, seu vocabulário, seus acentos), enfim, toda estratificação interna de cada língua em cada momento dado de sua existência histórica constituiu premissa indispensável do gênero romanesco. Eé graças a este plurilingüismo social e ao crescimento em seu solo de vozes diferentes que o romance orquestra todos os seus temas, todo o seu mundo objetal, semântico, figurativo e expressivo. (BAKHTIN, 1998, p. 74)

Podemos dizer, portanto, que a diversidade lingüística, tal como a concebe Bakhtin, é muito mais que a simples variedade de línguas nacionais claramente definidas entre si ou, como gostamos de definir, a língua materna e a língua estrangeira. Suas verdadeiras identidades se encontram na estratificação social. O solo fértil, a que se refere o autor, constitui-se no diálogo entre essas várias vozes que compõem o cenário plurilíngüe de uma dada realidade social. É do diálogo entre essas vozes que se nutre o romance, configurando assim o discurso do autor, os discursos dos narradores, os gêneros intercalados, os discursos das personagens. Assim, o plurilingüismo só pode existir quando as linguagens deixam de se ignorar mutuamente e passam a servir de fundo dialógico umas às outras. Somente desta forma é possivel superar a perspectiva monológica, isto é, a superação da "descentralização ideológico-verbal só ocorrerá quando a cultura nacional perder seu caráter fechado e autônomo, quando ela tomar consciência de si entre as outras culturas e línguas" (p. 166).

É nesse sentido que vemos alguns problemas na afirmação dos Parâmetros de que, em linhas gerais, o que a língua estrangeira vai fazer na escola é "....aumentar o conhecimento sobre linguagem que o aluno construiu sobre sua língua materna, por meio de comparações com a língua estrangeira em vários níveis" (p. 29).

É preciso que, ao pensarmos nesse conhecimento construído sobre a língua materna, estejamos atentos para uma compreensão de que, na verdade, não existe língua materna, assim como não existe o povo brasileiro, a não ser como uma abstração. Na realidade, nossos alunos falam português o tempo todo, estudam português na escola, ouvem notícias em português 
na televisão, escutam músicas em português no rádio, mas em cada uma dessas situações usa-se um português diferente. O que existe, na verdade, são as várias linguagens da estratificação social a que se referia Bakhtin, para além das diferenças dialetais. E o conhecimento que nossos alunos têm do português como língua materna é o conjunto aparentemente desordenado dessas várias linguagens. $\mathrm{Na}$ verdade, essas experiências estão mediadas pelos vários gêneros do discurso. E é sobre esse conjunto de experiências que o aluno vai construir algum conhecimento sobre a língua estrangeira, normalmente apresentada de forma mais ordenada, formal e, não raro, como um construto teórico sobre o qual se fala e se estuda, mas que parece não existir fora da sala de aula. É preciso, portanto, que a língua estrangeira se apresente para os nossos alunos como um conjunto de experiências ordenadas não pelo seu aspecto sistêmico, mas por seu caráter genérico, ou seja, é preciso recuperar o trabalho com o enunciado, organizado pelos mais variados gêneros do discurso. Só assim nossos alunos poderão construir algum conhecimento sobre a língua estrangeira a partir do seu conhecimento sobre a língua materna.

Esperamos, com estas observações acerca da teoria do Círculo de Bakhtin, mediadas pelas observações de outros autores, ter podido contribuir para ampliar os debates em torno da necessidade de precisão teóricometodológica no ensino de línguas. Porém, gostaríamos de finalizar, lembrando uma última vez o artigo de Faraco e Castro, reafirmando com eles, entre outras coisas, que o que devemos priorizar como professores de língua - materna ou estrangeira - é o compromisso de "levar para dentro da sala de aula - até onde o limite natural da escola permite - a realidade dinâmica das relações lingüísticas que estão acontecendo fora da escola" (p. 193).

Se tanto os professores de língua materna quanto os de línguas estrangeiras tivessem esse compromisso, seria mais fácil entender as palavras de Bakhtin quando ele diz que "as linguagens do plurilingüismo, como espelhos que apontam um para o outro, cada um dos quais refletindo a seu modo um pequeno pedaço, um cantinho do mundo, forçam a adivinhar e captar atrás dos seus aspectos mutuamente refletidos um mundo muito mais amplo, com muito mais planos e perspectivas do que seria possível a uma única linguagem, um único espelho" (BAKHTIN, 1998, p. 204). 


\section{REFERENCIAS}

BAKHTIN, M.; VOLOSHINOV, V. N. Marxismo e filosofia da linguagem: problemas fundamentais do método sociológico na ciência da linguagem. São Paulo: Hucitec, 1992.

BAKHTIN, M. Estética da criação verbal. São Paulo: Martins Fontes, 2000.

BAKHTIN, M. Questões de literatura e de estética. São Paulo: Hucitec, 1998.

BRASIL/MEC/SEF. Parâmetros Curriculares Nacionais $3^{\circ}$ e $4^{\circ}$ ciclos do ensino fundamental: língua estrangeira. Brasília: MEC/SEF, 1998.

FARACO, C. A.; CASTRO, G. Por uma teoria linguiística que fundamente o ensino de língua materna (ou de como apenas um pouquinho de gramática nem sempre é bom). Educar em Revista, Curitiba, n. 15, p. 179-194, 1999.

PENNYCOOK, A. Incommensurable discourses? Applied Linguistics, Oxford, v. 15, n. $2,1994$.

Texto recebido em 22 jul. 2002

Texto aprovado em 26 ago. 2002 